\title{
Overcoming the Bell-Shaped Dose-Response of Cannabidiol by Using Cannabis Extract Enriched in Cannabidiol
}

\author{
Ruth Gallily1, Zhannah Yekhtin'1, Lumír Ondřej Hanuš² \\ ${ }^{1}$ The Lautenberg Center for General and Tumor Immunology, The Hadassah Medical School, The Hebrew \\ University of Jerusalem, Jerusalem, Israel \\ ${ }^{2}$ Department of Medicinal and Natural Products, Institute for Drug Research, The Hadassah Medical School, \\ The Hebrew University of Jerusalem, Jerusalem, Israel \\ Email: ruthg@ekmd.huji.ac.il
}

Received 12 November 2014; accepted 7 February 2015; published 10 February 2015

Copyright (C) 2015 by authors and Scientific Research Publishing Inc.

This work is licensed under the Creative Commons Attribution International License (CC BY). http://creativecommons.org/licenses/by/4.0/

(c) () Open Access

\begin{abstract}
Cannabidiol (CBD), a major constituent of Cannabis, has been shown to be a powerful anti-inflammatory and anti-anxiety drug, without exerting a psychotropic effect. However, when given either intraperitoneally or orally as a purified product, a bell-shaped dose-response was observed, which limits its clinical use. In the present study, we have studied in mice the anti-inflammatory and anti-nociceptive activities of standardized plant extracts derived from the Cannabis sativa L., clone 202, which is highly enriched in CBD and hardly contains any psychoactive ingredients. In stark contrast to purified CBD, the clone 202 extract, when given either intraperitoneally or orally, provided a clear correlation between the anti-inflammatory and anti-nociceptive responses and the dose, with increasing responses upon increasing doses, which makes this plant medicine ideal for clinical uses. The clone 202 extract reduced zymosan-induced paw swelling and pain in mice, and prevented TNF $\alpha$ production in vivo. It is likely that other components in the extract synergize with CBD to achieve the desired anti-inflammatory action that may contribute to overcoming the bell-shaped dose-response of purified CBD. We therefore propose that Cannabis clone 202 (Avidekel) extract is superior over CBD for the treatment of inflammatory conditions.
\end{abstract}

\section{Keywords}

Cannabis sativa L. Clone 202, Cannabidiol, Anti-Inflammation, Anti-Nociceptive, TNF $\alpha$ 


\section{Introduction}

Inflammation and pain have accompanied human life for ages. Many anti-inflammation and anti-pain medications and various approaches have been employed through the centuries and in recent time. Many of used drugs, however, impose severe side effects. Cannabis from various origins and species has been employed in various forms as anti-pain agents for thousands of years [1]-[3]. One example is the legitimated drug Sativex ${ }^{\circledR}$ (Nabiximols) that is used in the treatment of severe spasticity in patients with multiple sclerosis [4]. Two other drugs, Marinol (Dronabinol) and Cesamet, have been approved for use in cancer-related anorexia-cachexia syndrome as well as for nausea and vomiting [3]. But a major disadvantage of Cannabis phytomedicine is its psychoactive effects due to the presence of $\Delta^{9}$-Tetrahydrocannabinol (THC).

Recently, a science-based approach is being conducted to specify the benefits of Cannabis and its many constituents. A Cannabis plant contains hundreds of different chemicals with about 60 - 80 chemicals known as cannabinoids [5]. The major Cannabis psychoactive molecule is the $\Delta^{9}$-tetrahydrocannabinol, known as THC, which binds with high affinity $\left(\mathrm{K}_{\mathrm{i}}=3-5 \mathrm{nM}\right)[6]$ to both the cannabinoid CB1 receptor expressed in the brain and the $\mathrm{CB} 2$ receptor expressed on cells of the immune system [7]. Another major constituent is Cannabidiol (CBD) which is devoid of psychotropic effects and binds only with very low affinity $\left(\mathrm{K}_{\mathrm{i}}>10 \mu \mathrm{M}\right)[6]$ to the $\mathrm{CB} 1 / \mathrm{CB} 2$ receptors. The other cannabinoids are present in minute amounts. Stimulation of CB1 receptor is responsible for the Cannabis psychoactivity, while activation of the CB2 receptor leads to attenuated inflammation, decreased injury and accelerated regeneration in many disease states [7]. CBD has been shown to activate central nervous system's limbic and paralimbic regions, which can reduce autonomic arousal and feeling of anxiety [3]. This is in contrast to THC which can be anxiogenic [3]. CBD has also been shown to have anti-emetic, anti-inflammatory and anti-psychotic effects [3]. Studies are looking for potential benefits of phytocannabinoids in management of neuropathic pain, hypertension, post-stroke neuroprotection, multiple sclerosis, epilepsy and cancer [3]. Doses up to $1500 \mathrm{mg}$ per day as well as chronic use of CBD have been reported as being well tolerated by humans [3].

During the last 10 - 15 years, many studies have focused on the anti-inflammatory effects of purified CBD in various animal models, including rheumatoid arthritis, diabetes type 1, inflammatory bowel disease and multiple sclerosis [8]-[13]. These studies showed that purified CBD gives a bell-shaped dose-response curve. Healing was only observed when CBD was given within a very limited dose range, whereas no beneficial effect was achieved at either lower or higher doses. This trait of purified CBD imposes serious obstacles in planning human and animal studies. The aim of the present study was to find a CBD source that could eliminate the bell-shaped dose-response of purified CBD. We found that by using standardized plant extracts from the Cannabis clone 202 obtained from Tikun Olam, Israel, which is highly enriched in CBD and barely contains THC, a correlative antiinflammatory and anti-pain dose-response could be achieved when applied either intraperitoneally or orally in an inflammatory mouse model.

\section{Material and Methods}

\subsection{CBD and Cannabis Clone 202 (Avidekel) Extract}

Purified CBD was purchased from THC Pharm. GmbH, Frankfurt, Germany. Cannabis sativa L. flowers from the clone 202 (Avidekel) rich in CBD while low in any psychotropic constituents was supplied by Tikun Olam Company (a government-approved farm growing medicinal Cannabis), Israel. CBD-enriched extract was prepared from the flowers of Cannabis clone 202 grown under controlled temperature and light conditions. 100\% ethanol $(20 \mathrm{ml})$ was added to the chopped Cannabis dry flowers $(200 \mathrm{mg})$ for 24 - $48 \mathrm{hrs}$, with occasional shaking at room temperature. Following filtration, samples were taken for analysis. Ethanol solutions of Cannabis clone 202 extracts $(10 \mathrm{mg} / \mathrm{ml}-20 \mathrm{mg} / \mathrm{ml})$ were kept at $-20^{\circ} \mathrm{C}$ in the dark. The extract was evaporated on Rotavapor (BÜCHI Labortechnik AG, Switzerland). For intraperitoneal injection, the dried Cannabis clone 202 extract was emulsified in a vehicle composed of ethanol:Cremophor:saline at a 1:1:18 ratio. Purified CBD was emulsified in the same vehicle. For oral administration, the dried Cannabis clone 202 extract and the purified CBD were dissolved in olive oil.

\subsection{Analysis of the Cannabis Clone 202 Extract by Thin-Layer Chromatography (TLC)}

Cannabis clone 202 extract $(1 \mu \mathrm{l})$ was separated on TLC Silica Gel 60 F254 aluminium sheets (Merck, Darm- 
stadt, Germany) using hexane:dioxane (4:1) as a solvent in a chamber of $13 \times 9 \times 12 \mathrm{~cm}$. The separated components were detected by spraying the plates with a freshly prepared solution of $0.5 \mathrm{~g}$ Fast Blue B (D9805, Sigma) in acetone/water $(9: 1 ; \mathrm{v} / \mathrm{v})$. Cannabinoids in the dried plant material predominately appeared as cannabinoid acids. The TLC analysis shows two major spots corresponding to the acid and neutral form of CBD, respectively, with only a minor spot corresponding to the acid form of THC (Figure 1(a)).

\subsection{Analysis of the Cannabis Clone 202 Extract by Gas Chromatography and Mass Spectrophotometry (GC/MS)}

For analysis of the composition of the ethanol extracts of medicinal Cannabis clone 202, the ethanol was evaporated and the resin dissolved in $20 \mathrm{ml}$ of methanol and filtered through cotton in a capillary. The concentration of the extract was adjusted to $1 \mathrm{mg} / \mathrm{ml}$ to which $50 \mu \mathrm{g}$ internal standard (Tetracosane, Acros Organics, USA) was added. One $\mu \mathrm{l}$ of this sample was applied for the GC/MS analysis. The quantitative analysis of the samples by GC/MS was performed in a Hewlett Packard G 1800B GCD system with a HP-5971 gas chromatograph with electron ionization detector. The software used was GCD Plus ChemStation. The column used was SPB-5 (30 m $\times 0.25 \mathrm{~mm} \times 0.25 \mu \mathrm{m}$ film thickness). Experimental conditions were: inlet, $250^{\circ} \mathrm{C}$; detector, $280^{\circ} \mathrm{C}$; splitless injection/purge time, $1.0 \mathrm{~min}$; initial temperature, $100^{\circ} \mathrm{C}$; initial time, $2.0 \mathrm{~min}$; rate, $10^{\circ} \mathrm{C} / \mathrm{min}$; final temperature, $280^{\circ} \mathrm{C}$. The helium flow rate was $1 \mathrm{ml} / \mathrm{min}$. Calibration curve was made from 25.0 to $100 \mu \mathrm{g} / \mathrm{ml} \mathrm{Cannabidiol}$ (CBD), $\Delta^{9}$-Tetetrahydrocannabinol (THC) or Cannabinol (CBN) together with $50.0 \mu \mathrm{g} / \mathrm{ml}$ tetracosane as internal standard. The cannabinoid composition of Cannabis clone 202 extract is presented in Figure 1(b), Figure 1(c) and Table 1.

\subsection{Commercial Anti-Nociceptive and Anti-Inflammatory Drugs}

The non-steroid anti-inflammatory drug (NSAID) aspirin (acetylsalicylic acid) was purchased from Sigma and dissolved in olive oil. Fifty mg of aspirin was given per os per $\mathrm{kg}$ in a volume of $40 \mu \mathrm{l}$. The opioid anti-nociceptive Tramadol hydrochloride was obtained from Grunenthal and dissolved in saline. Five mg of Tramadol was given per os per $\mathrm{kg}$.

(a)

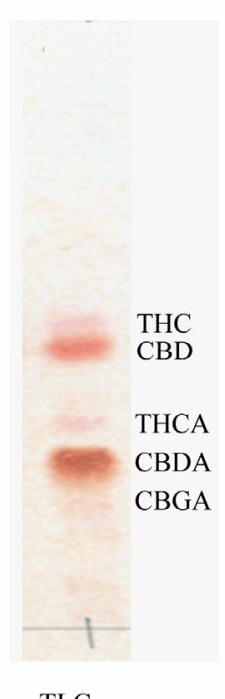

(b)

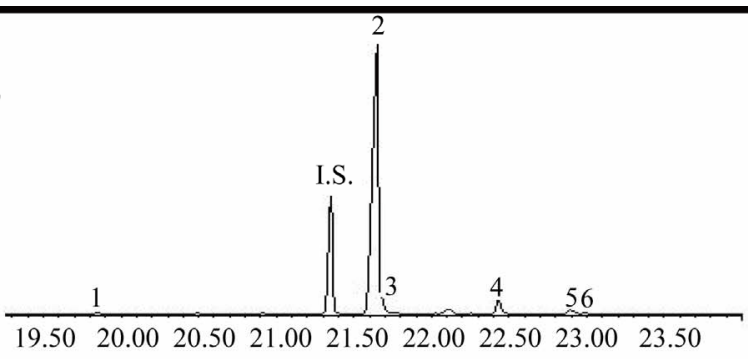

(c)

$$
\text { I.S. } 2
$$

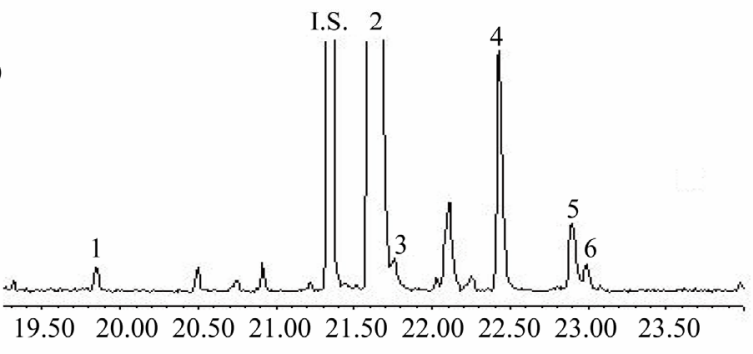

GC/MS chromatogram

Figure 1. (a) TLC analysis of clone 202 extract. $1 \mu \mathrm{l}$ of the extract was run on TLC as described in the Method section. $\mathrm{CBD}=$ Cannabidiol. CBDA = Cannabidiolic acid; (b) (c) GC/ MS chromatograms of an extract from Cannabis clone 202. (b) The full chromatogram. (c) Magnification of weaker signals. Number keys: 1: Cannabidivarol (CBDV); 2: Cannabidiol (CBD); 3: Cannabichromene (CBC); 4: $\Delta^{9}$-Tetrahydrocannabinol $\left(\Delta^{9}-\mathrm{THC}\right)$; 5: Cannabigerol $(\mathrm{CBG}) ; 6$ : Cannabinol (CBN); I.S.-Internal Standard (Tetracosane). 
Table 1. The percentage of main phytocannabinoids found in clone 202 extract according to GC/MS analysis (see Figures 1(b)-(c)).

\begin{tabular}{cc}
\hline Phytocannabinoid & Content \\
\hline Cannabidiol (CBD) & $17.9 \%$ \\
$\Delta^{9}$-Tetrahydrocannabinol $\left(\Delta^{9}-\mathrm{THC}\right)$ & $1.1 \%$ \\
Cannabichromene (CBC) & $1.1 \%$ \\
Cannabigerol (CBG) & $0.2 \%$ \\
Cannabinol (CBN) & Traces \\
Cannabidivarol (CBDV) & Traces
\end{tabular}

As cannabinoid acids during injection to the GC/MS decarboxylate, the results are a total sum of neutral cannabinoids and cannabinoid acids that have decarboxylated into neutral cannabinoids. The content is the mass fraction $(\% \mathrm{w} / \mathrm{w})$ of the given constituent in the extract.

\subsection{Animals}

Six to eight week old female Sabra mice (Israel) were maintained in the SPF unit of the Hebrew UniversityHadassah Medical School, Jerusalem, Israel. The experimental protocols were approved by the Animal Care Ethical Committee of the Hebrew University-Hadassah Medical School, Jerusalem, Israel. The animals were maintained on standard pellet diet and water ad libitum. The animals were maintained at a constant temperature $\left(20^{\circ} \mathrm{C}-21^{\circ} \mathrm{C}\right)$ and a $12 \mathrm{~h} \mathrm{light} /$ dark cycle.

\subsection{Induction of Paw Inflammation in Mice and Treatment with Purified CBD or Clone 202 Extract}

To induce inflammation, $40 \mu \mathrm{l}$ of $1.5 \%$ (w/v) zymosan A (Sigma) suspended in $0.9 \%$ saline was injected into the sub-planter surface of the right hind paw of the mice. Immediately after zymosan injection, CBD or Cannabis clone 202 extract was injected intraperitoneally (i.p.) or given orally. For intraperitoneal injection, these agents were dissolved in $0.1 \mathrm{ml}$ vehicle containing ethanol:Cremophore:saline at a ratio of 1:1:18. Control mice were injected with the vehicle only. For per os administration, the agents were dissolved in olive oil, each mouse receiving $40 \mu \mathrm{l}$. Control mice got $40 \mu \mathrm{l}$ olive oil. After 2, 6 and $24 \mathrm{hrs,} \mathrm{paw} \mathrm{swelling} \mathrm{and} \mathrm{pain} \mathrm{perception} \mathrm{were}$ measured. Serum TNF $\alpha$ titers were determined after 24 hrs. The effects of CBD and Cannabis clone 202 extract were compared to those of aspirin ( $50 \mathrm{mg} / \mathrm{kg}$ per os) and tramadol (5 mg/kg, i.p.).

\subsection{Measurement of Oedema Formation}

The paw swelling (thickness) was measured by calibrated calipers $(0.01 \mathrm{~mm}), 2,6$ and 24 hrs following injections of zymosan alone or with CBD or Cannabis clone 202 extracts.

\subsection{Pain Assay}

The hyperalgesia was evaluated by the paw withdrawal von Frey test at 2, 6, and $24 \mathrm{hrs}$ following injections of zymosan and/or the test compounds. In the von Frey nociceptive filament assay, von Frey calibrated monofilament hairs of logarithmically incremental stiffness $(0.008-300 \mathrm{~g}$ corresponding to $1.65-6.65 \mathrm{log}$ of force). In our study, only 1.4 - $60 \mathrm{~g}$ corresponding to 4.17 to $5.88 \mathrm{log}$ of force was used, to test the mouse sensitivity to a mechanical stimulus on the swollen paw. The measurements were performed in a quiet room. Before paw pain measurements, the animals were held for $10 \mathrm{sec}$. The trained investigator applied the filament to the central area of the hind paw with gradual increasing size. The test consisted of poking the middle of the hind paw to provoke a flexion reflex followed by a clear flinch response after paw withdrawal. Each one of the von Frey filaments was applied for approximately $3-4 \mathrm{~s}$ to induce the end-point reflex. The first testing was done by using the force filament of $1.4 \mathrm{~g}$. If there was no withdrawal response, the next higher stimulus was tried. The mechanical threshold force (in grams (g)) was defined as the lowest force imposed by two von Frey monofilaments of various sizes, required to produce a paw retraction. The untreated left hind paw served as a control. 


\subsection{Tumor Necrosis Factor $\alpha$ (TNF $\alpha$ ) Plasma Levels}

Plasma levels of TNF $\alpha$ were measured using a mouse TNF $\alpha$ ELISA kit (R\&D System), according to the manufacturer's instructions.

\subsection{Statistical Analysis}

The results are presented as average \pm standard error. Mice treated with CBD or Cannabis clone 202 extracts were compared with control mice receiving the vehicle only. Statistical significance was calculated using the ANOVA analysis of variance and Wilcoxon signed-rank test. Differences between the various doses of CBD and clone 202 extracts were analyzed for significance using the repeated measures ANOVA procedure with Post-Hoc test. All tests were 2-tailed and a p-value below 0.05 was considered statistically significant. A minimum of three to four animals was used in each treatment group for each experiment unless otherwise stated. Each experiment was performed at least three times. The graphs represent the average of all mice from the three different experiments. Thus, each bar corresponds to the average of 10 - 12 mice for each treatment group, for each time point, unless otherwise stated.

\section{Results}

\subsection{Effect of CBD and CBD-Enriched Clone 202 Extract on Inflammation and Hyperalgesia (Pain Sensation)}

In this study we have used the well-accepted mouse model of zymosan-induced inflammation [14] to investigate the anti-inflammatory and anti-nociceptive activities of Cannabis clone 202 extract versus purified CBD. The extent of hind paw swelling was determined 2, 6 and 24 hrs following paw injection of $60 \mu \mathrm{g}$ zymosan together with either intraperitoneal injection or per os administration of various amounts of either purified CBD or Cannabis clone 202 extract, as indicated in the graphs (Figure 2, Figure 3). Following intraperitoneal injection of 1 , 5,25 and $50 \mathrm{mg} / \mathrm{kg}$ of purified CBD, a bell-shaped dose-response is observed (Figure 2(a)). The maximum inhibition of inflammation occurred after an injection of $5 \mathrm{mg} / \mathrm{kg}$ CBD with $50 \%$ and $57 \%$ inhibition after 6 and $24 \mathrm{hrs}$, respectively $(\mathrm{p}<0.001)$, while a lower dose $(1 \mathrm{mg} / \mathrm{kg})$ being ineffective and higher doses $(25$ and 50 $\mathrm{mg} / \mathrm{kg}$ ) being less effective with $20 \%-25 \%$ and $14 \%-28 \%$ inhibition only, after 6 and 24 hrs, respectively (Figure 2(a)). In accordance with these findings, the anti-nociceptive effect, as determined by the von Frey monofilament assay, peaked at $5 \mathrm{mg} / \mathrm{kg} \mathrm{CBD}(\mathrm{p}<0.001)$ (Figure 2(c)). The anti-nociceptive effect occurred prior $(2 \mathrm{hrs})$ to inhibition of swelling $(6 \mathrm{hrs})$, and peaked at $6 \mathrm{hrs}$. Higher concentrations of CBD had less anti-nociceptive effects (Figure 2(c)), again getting a bell-shaped dose-response. However, when clone 202 extract was used, a correlative dose-response was observed with increased inhibition of inflammation upon increased doses of the extract, reaching $43 \%$ and $64 \%$ inhibition at $25 \mathrm{mg}$ and $50 \mathrm{mg}$, respectively, after $24 \mathrm{hrs}$ (p $<0.001$ ) (Figure 2(b)). These two dosages of clone 202 extract also showed strong anti-nociceptive effects after 6 and 24 hrs $(\mathrm{p}<0.001)$ (Figure 2(d)). Although the anti-inflammatory effect of clone 202 extract was higher at 50 $\mathrm{mg} / \mathrm{kg}$ than at $25 \mathrm{mg} / \mathrm{kg}$ with a $\mathrm{p}=0.001$, the anti-nociceptive effect was only slightly higher $(\mathrm{p}=0.01)$, suggesting that a plateau has been reached. The clone 202 extract was more efficient for alleviating the pain than $\mathrm{CBD}(\mathrm{p}=0.01)$ (Figure 2(d) versus Figure 2(c)).

When CBD or Cannabis clone 202 extract was given orally, a similar response was observed. Namely, CBD gives a bell-shaped dose-response with an optimal inhibitory effect at $25 \mathrm{mg} / \mathrm{kg}(\mathrm{p}<0.001)$ (Figure 3(a) and Figure 3(c)), whereas Cannabis clone 202 extract provides a correlative dose-response curve with a maximum effect on swelling and pain relief at 50 and $150 \mathrm{mg} / \mathrm{kg}$, respectively $(\mathrm{p}<0.001)$ (Figure 3(b) and Figure 3(d)). Significant pain relief was already obtained with an oral clone 202 extract dose of $50 \mathrm{mg} / \mathrm{kg}$ (Figure 3(d)) that corresponds to about $10 \mathrm{mg} / \mathrm{kg}$ CBD (Table 1 ), while $25 \mathrm{mg} / \mathrm{kg}$ of purified CBD was needed to achieve the same effect (Figure 3(c)). This suggests for a better usage of clone 202 extract.

It should be noted that agents taken per os need to go through the enterohepatic route prior to exerting their effects, where the absorption rate and first-pass liver metabolism affect the blood drug level [15]. This may explain the higher doses required and the delayed response in comparison with the parenteral route, where the agents are immediately available for the blood circulation. The anti-inflammatory and anti-nociceptive effects peak at 6 hrs, which accords with the pharmacokinetics and pharmacodynamics of cannabinoids described by Grotenhermen [15]. 

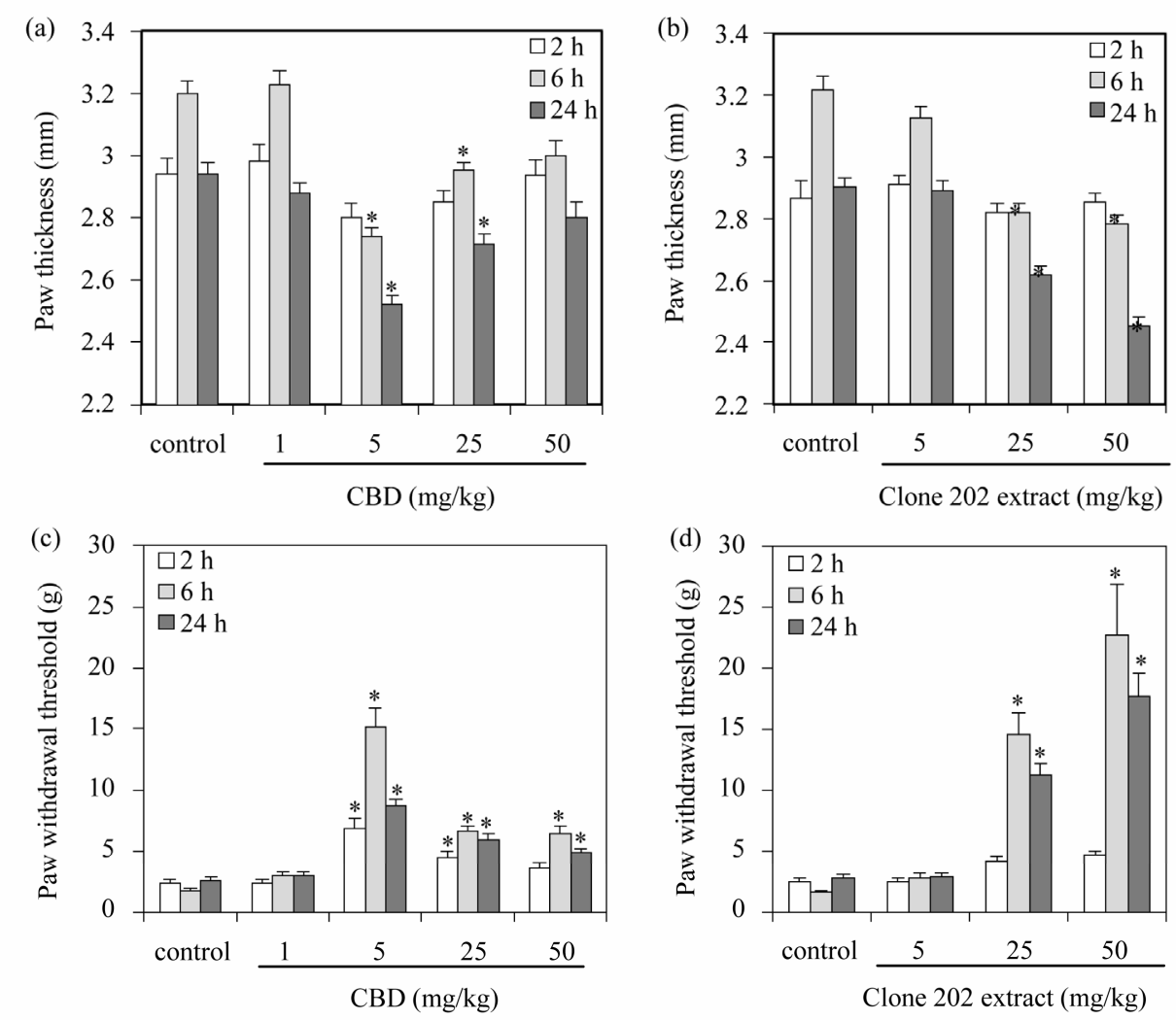

Figure 2. Anti-inflammatory and anti-nociceptive effects of intraperitoneally injected CBD and CBDenriched clone 202 extract. (a) (b) Prevention of zymosan-induced swelling of hind paw. 1.5\% zymosan in $40 \mu \mathrm{l}$ was injected into the sub-planter surface of the right hind paw. Immediately thereafter, CBD (a) or Cannabis clone 202 extract (b) was injected intraperitoneally. The paw thickness indicative for paw swelling was measured 2, 6 and $24 \mathrm{hrs}$ thereafter. The paw thickness of untreated mice was $2.0-2.2 \mathrm{~mm}$, which made the baseline of the graph. $\mathrm{N}=12$ for each time point. ${ }^{*} \mathrm{p}<0.001 \mathrm{com}$ pared to control mice. $\mathrm{p}<0.001$ for $50 \mathrm{mg} / \mathrm{kg}$ vs $25 \mathrm{mg} / \mathrm{kg}$ of clone 202 extract at $24 \mathrm{hrs}$; (c) (d) Antipain effect of CBD (c) and Cannabis clone 202 extract (d). The hyperalgesia was measured by using the von Frey nociceptive filament assay. The higher the paw withdrawal threshold, the higher is the anti-nociceptive effect of the drug. The experiments were repeated three times, each experiment with 4 mice in each treatment group. The graphs presents the average of all mice in the three experiments, meaning that the $\mathrm{N}=12$ for each time point. The bars represent standard error. ${ }^{*} \mathrm{p}<0.001$ compared to control mice. $\mathrm{p}<0.01$ for $50 \mathrm{mg} / \mathrm{kg}$ vs $25 \mathrm{mg} / \mathrm{kg}$ of clone 202 extract at $24 \mathrm{hrs}$. $\mathrm{p}<0.01$ for clone 202 extract vs CBD.

\subsection{Suppression of TNF $\alpha$ Production by CBD and Clone 202 Extract}

$\mathrm{TNF} \alpha$ is a well-known pro-inflammatory cytokine secreted by activated macrophages upon inflammation that has been shown to be involved in initiation and amplification of inflammatory processes that ultimately leads to oedema [16]. Therefore, it was important to analyze the effect of CBD and clone 202 extracts on TNF $\alpha$ production. To this end, mice sera were analyzed for TNF $\alpha$ concentration by ELISA $24 \mathrm{hrs}$ after treatment with zymosan in the absence or presence of CBD or clone 202 extract. When comparing the TNF $\alpha$ sera level in mice 24 hrs after injection of increasing doses of purified CBD, a bell-shaped dose-response curve of TNF $\alpha$ production was observed, with a maximum inhibitory effect $(43 \%)$ achieved at $5 \mathrm{mg} / \mathrm{kg}(\mathrm{p}<0.001)$, while no inhibition was observed at either lower $(1 \mathrm{mg} / \mathrm{kg})$ or higher $(25$ and $50 \mathrm{mg} / \mathrm{kg}$ ) doses (Figure 4(a)). In contrast, following injection of CBD-enriched clone 202 extract to mice, a clear dose dependent response was apparent. Increased inhibition of TNF $\alpha$ production (39\%; $46 \%$ and $57 \%$, respectively) was observed following injections with increasing amounts of extract $(5 \mathrm{mg} / \mathrm{kg}, 25 \mathrm{mg} / \mathrm{kg}$ and $50 \mathrm{mg} / \mathrm{ml}$, respectively) with a p value less than 0.001 (Figure 4(b)). Already at $5 \mathrm{mg} / \mathrm{kg}$ did clone 202 extract lead to a strong reduction in TNF $\alpha$ production (Figure 4(b)), 

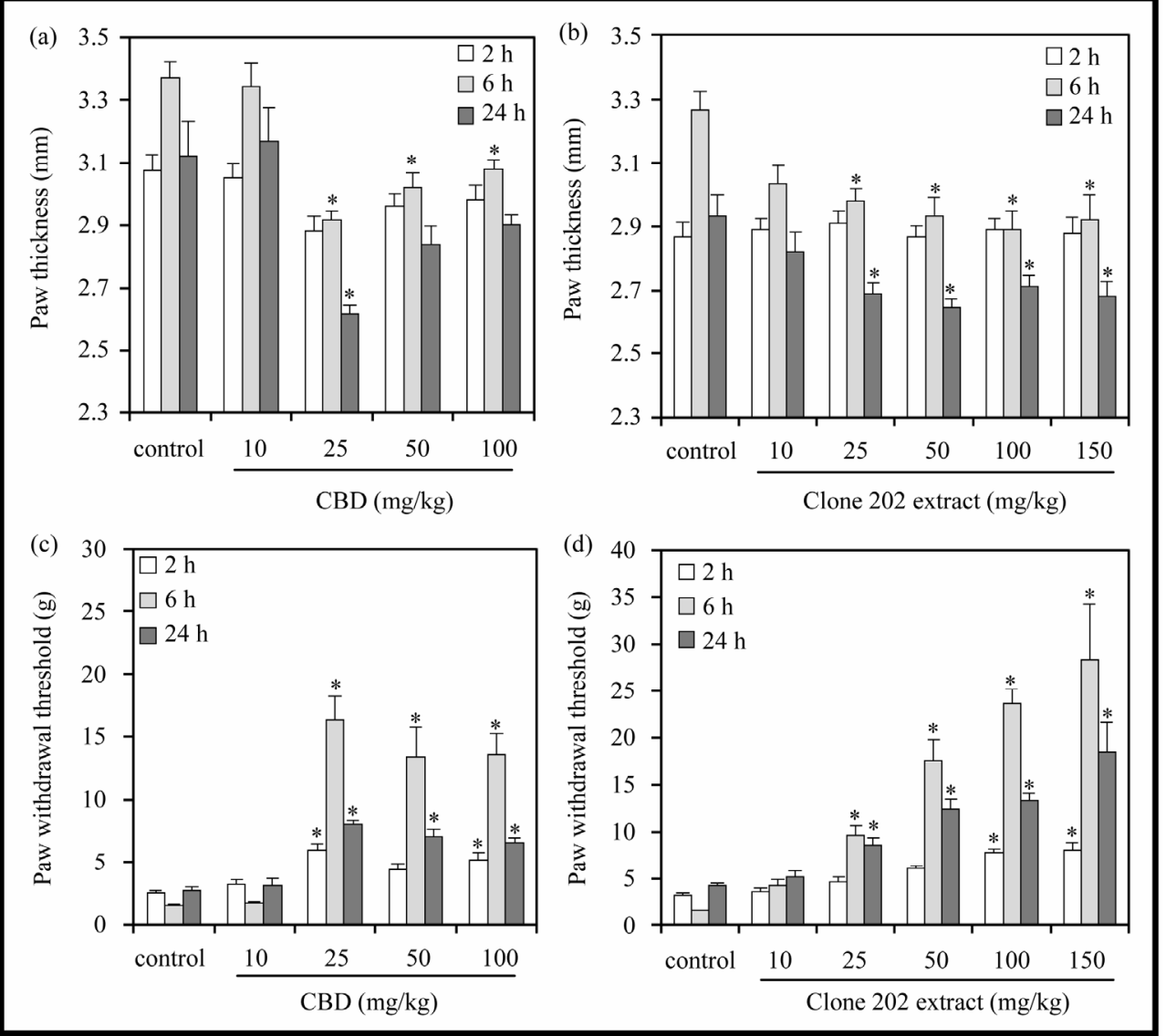

Figure 3. Anti-inflammatory and anti-nociceptive effects of CBD and CBD-enriched clone 202 extract administrated per os. (a) (b) Prevention of zymosan-induced swelling of hind paw. $1.5 \%$ zymosan in $40 \mu \mathrm{l}$ was injected into the sub-planter surface of the right hind paw. Immediately thereafter, CBD (a) or Cannabis clone 202 extract (b) was given per os dissolved in olive oil ( $40 \mu \mathrm{l})$. The paw thickness indicative for paw swelling was measured 2, 6 and $24 \mathrm{hrs}$ thereafter. The paw thickness of untreated mice was $2.0-2.2 \mathrm{~mm}$, which made the baseline of the graph. $\mathrm{N}=12$ for each time point. ${ }^{*} \mathrm{p}<0.001$ in comparison to control mice. The anti-inflammatory effects of $25,50,100$ and 150 $\mathrm{mg} / \mathrm{kg}$ of clone 202 extract were similar; (c) (d) Anti-pain effect of CBD (c) and Cannabis clone 202 extract (d) when given orally. The hyperalgesia was measured by using the von Frey nociceptive filament assay. The higher the paw withdrawal threshold, the higher is the anti-nociceptive effect of the drug. The experiments were repeated three times, each experiment with 4 mice in each treatment group. The graphs presents the average of all mice in the three experiments, meaning that the $\mathrm{N}=12$ for each time point. The bars represent standard error. ${ }^{*} \mathrm{p}<0.001$ in comparison to control mice. $\mathrm{p}<$ 0.001 for $50 \mathrm{mg} / \mathrm{kg}$ clone 202 extract (containing $8.9 \mathrm{mg} / \mathrm{kg} \mathrm{CBD}$ ) vs $10 \mathrm{mg} / \mathrm{kg}$ purified CBD. $\mathrm{p}<$ 0.05 of $100 \mathrm{mg} / \mathrm{kg}$ and $150 \mathrm{mg} / \mathrm{kg}$ vs $50 \mathrm{mg} / \mathrm{kg}$ of clone 202 extract at $6 \mathrm{hrs}$, indicating a dosedependent effect.

even though this dose was insufficient in reducing paw swelling (Figure 2(b)) or relieve pain (Figure 2(d)). At least $25 \mathrm{mg} / \mathrm{kg}$ extract, which corresponds to about $5 \mathrm{mg} \mathrm{CBD}$, was required to achieve the anti-inflammatory effect. These data show that TNF $\alpha$ secretion is more sensitive to inhibition by clone 202 extract, than paw swelling and pain.

Similar to the results obtained with intraperitoneal injection, orally administrated CBD gave a bell-shape response, with an optimal response using $25 \mathrm{mg} / \mathrm{kg}(\mathrm{p}<0.001)$, while higher or lower doses had less effect (Figure 4(c)). In contrast, orally delivered clone 202 extract showed an increased inhibitory effect on TNF $\alpha$ production with increased doses (Figure 4(d)). Already at $25 \mathrm{mg} / \mathrm{kg}$ an inhibition of $48 \%$ was achieved that increased further to $66 \%$ when given $150 \mathrm{mg} / \mathrm{kg}$ clone 202 extract (Figure 4(d)). The inhibition of TNF $\alpha$ production was much stronger than the inhibitory effect on paw swelling of $27 \%-35 \%$. 

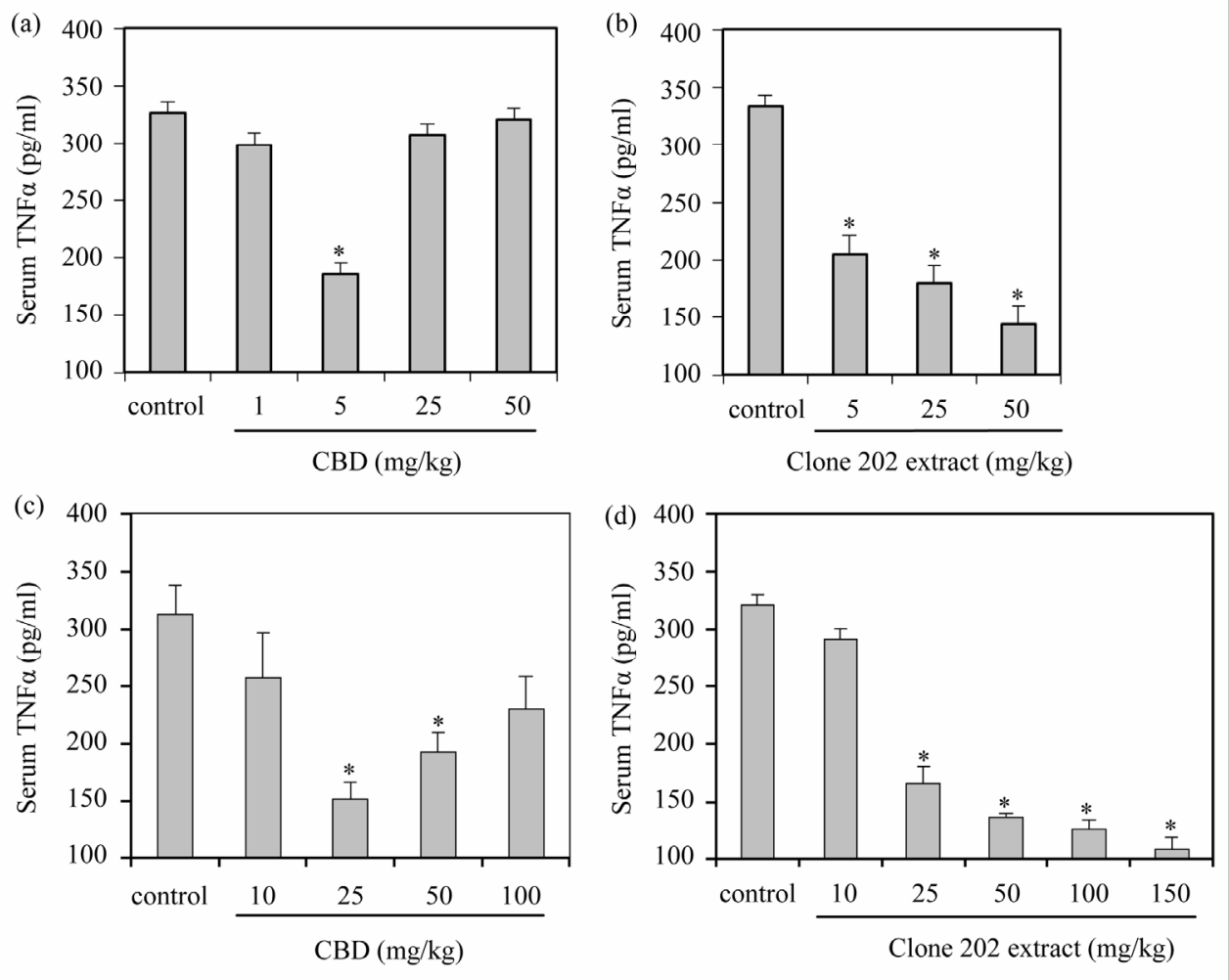

Figure 4. Prevention of zymosan-induced TNF $\alpha$ production by purified CBD and clone 202 extract. (a) (b) Twenty four hours after injecting zymosan and an intraperitoneal dose of CBD (a) or clone 202 extract (b), or a per os dose of CBD (c) or clone 202 extract (d), the TNF $\alpha$ concentration in the serum was determined by ELISA. The experiments were repeated three times, each experiment with 4 mice in each treatment group. The graphs presents the average of all mice in the three experiments, meaning an $\mathrm{N}=12$ for each treatment. TNF $\alpha$ serum level of untreated mice was $15 \mathrm{pg} / \mathrm{ml}$. The bars represent standard error. ${ }^{*} \mathrm{p}<0.001$ in comparison to control mice. $\mathrm{p}<0.01$ when comparing clone 202 extract with purified CBD. $\mathrm{p}<0.01$ when comparing an increasing doses of clone 202 extract, emphasizing a dose-dependent effect.

\subsection{Comparison of CBD and Cannabis Clone 202 Extract with Commercial Anti-Nociceptive and Anti-Inflammatory Drugs}

Since Cannabis clone 202 extract has profound anti-inflammatory and anti-nociceptive effects as described above, it was important to compare its potency with commercial anti-nociceptive and anti-inflammatory drugs. We chose to use tramadol, a strong atypical opioid analgesic drug, and aspirin, a well-known non-steroid antiinflammatory drug (NSAID) that is also a pain reliever. Immediately after zymosan injection, mice were treated with aspirin (50 mg/kg per os), tramadol (5 mg/kg i.p.), CBD (5 mg/kg i.p.) or clone 202 extract $(50 \mathrm{mg} / \mathrm{kg}$ i.p.). While aspirin had a moderate effect on paw swelling $(\mathrm{p}<0.001$ at $6 \mathrm{~h}$ ), tramadol barely had any effect (Figure 5(a)). Both CBD and clone 202 extract markedly prevented paw swelling to a much larger extent than aspirin (p $<0.005$ ) (Figure 5(a)). As expected, aspirin and tramadol had a strong anti-nociceptive effect that exceeded that of CBD and clone 202 extract $(\mathrm{p}<0.01$ ) (Figure 5(b)). Aspirin, but not tramadol, showed a slight inhibitory effect on TNF $\alpha$ production, that was negligible in comparison to the strong inhibitory effect of CBD and clone 202 extract $(p<0.01)$ (Figure 5(c)). Thus, CBD and clone 202 extract are endowed with different traits than aspirin and tramadol, making them superior with respect to anti-inflammatory properties.

\section{Discussion}

In this manuscript we have observed different dose-response patterns when using purified CBD or plant extract 


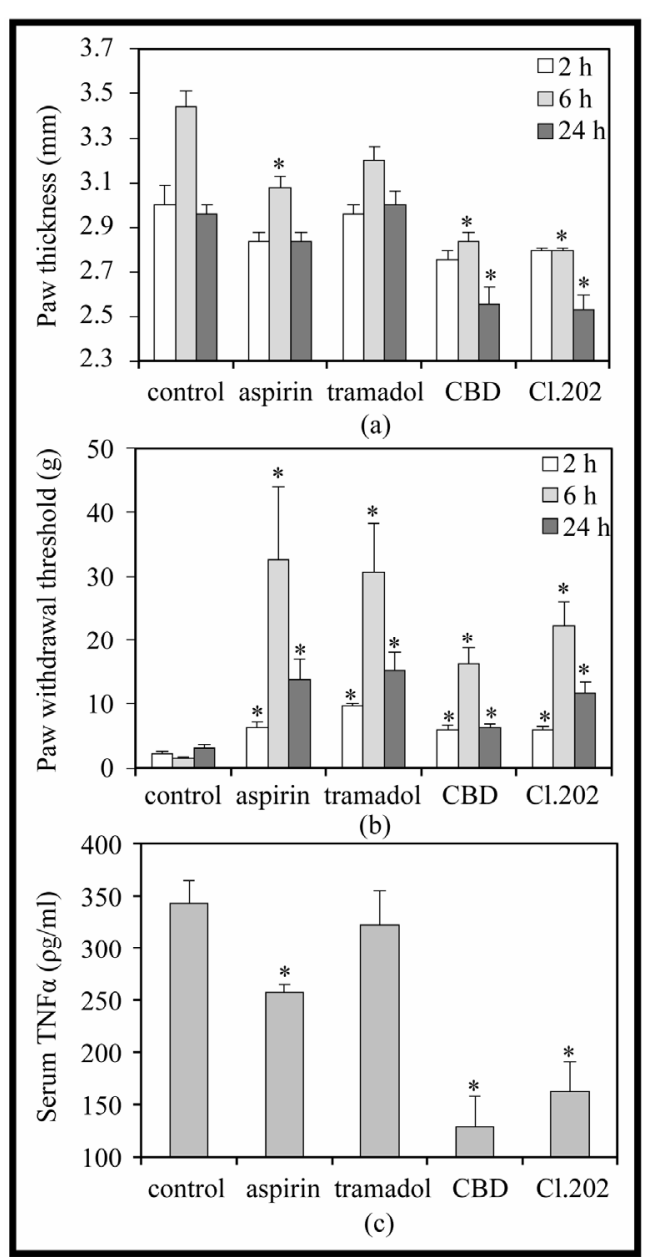

Figure 5. Comparison of anti-inflammatory and anti-nociceptive effects of CBD and Cannabis clone 202 extract with the commercial drugs aspirin and tramadol. (a) Prevention of zymosan-induced swelling of hind paw. $1.5 \%$ zymosan in $40 \mu$ was injected into the sub-planter surface of the right hind paw. Immediately thereafter, aspirin $(50 \mathrm{mg} / \mathrm{kg}$ per os $)$, tramadol $(5 \mathrm{mg} / \mathrm{kg}$ i.p.), CBD ( $5 \mathrm{mg} / \mathrm{kg}$ i.p.) or Cannabis clone 202 extract $(50 \mathrm{mg} / \mathrm{kg}$ i.p.) was given. The paw thickness indicative for paw swelling was measured 2, 6 and $24 \mathrm{hrs} \mathrm{later.} \mathrm{The} \mathrm{paw} \mathrm{thickness} \mathrm{of}$ untreated mice was $2.0-2.2 \mathrm{~mm}$, which made the baseline of the graph. $\mathrm{N}=5$ for each time point of each treatment group. ${ }^{*} p<0.001$ in comparison to control mice. $p<0.005$ when comparing CBD and clone 202 extract with aspirin and tramadol; (b) Anti-pain effect of aspirin, tramadol, CBD and Cannabis clone 202 extract in mice treated as described in paragraph A. The hyperalgesia was measured by using the von Frey nociceptive filament assay. The higher the paw withdrawal threshold, the higher is the anti-nociceptive effect of the drug. $\mathrm{N}=5$ for each time point of each treatment group. The bars represent standard error. ${ }^{*} \mathrm{p}<0.001$ in comparison to control mice. $\mathrm{p}<0.05$ when comparing CBD and clone 202 extract with aspirin and tramadol; (c) The TNF $\alpha$ serum concentration at $24 \mathrm{hrs}$ in mice that were treated as described in paragraph A. N $=5$ for each treatment. The bars represent standard error. ${ }^{*} \mathrm{p}<0.001$ in comparison to control mice. $\mathrm{p}<0.01$ when comparing CBD and clone 202 extract with aspirin and tramadol.

of the Cannabis sativa L. clone 202, which is highly enriched in CBD. Purified CBD showed a bell-shaped dose-response, where a therapeutic response could only be achieved at a certain concentration. This narrow therapeutic window makes it difficult to use CBD in the clinics as a single agent. Therefore, we sought for a better preparation that can utilize the favorable therapeutic effects of CBD. We observed that plant extracts of the nonpsychotropic clone 202 could fit this aim. A dose-dependent response was observed on all three parameters tested: namely, the extract prevented zymosan-induced paw oedema, zymosan-induced pain and zymosaninduced TNF $\alpha$ production in mice, with an improved therapeutic effect upon increased dosages. Thus, the limi- 
tation with purified CBD could be overcome when presented together with other natural components of the plant. Of note, TNF $\alpha$ secretion was more sensitive to clone 202 extract inhibition than paw swelling and pain.

Our finding that it is possible to get a correlative dose-response using Cannabis clone 202 extracts, makes it possible to use it in many pathological conditions. We suggest that clone 202 extracts may be a suitable substitute for the current used Cannabis strain in the clinics, especially taking into account that it does not have any psychotropic adverse effects. Following the clinical improvement by the clone 202 extracts, more tedious experiments with CBD might be planned.

Our findings that $\mathrm{CBD}$ in the presence of other plant constituents improve the dose-response are supported by some recent reports showing that CBD in a standardized Cannabis sativa extract is more potent or efficacious than pure CBD [17]-[19]. These research groups studied the anti-proliferative effect of CBD on tumor cells [17] [19] and the inhibitory effect of CBD on bladder contractility [18]. The higher efficiency of plant extract might be explained by additive or synergistic interactions between CBD and minor phytocannabinoids or non-cannabinoids presented in the extracts. Other phytocannabinoids, including Tetrahydrocannabivarin, Cannabigerol and Cannabichromene, exert additional effects of therapeutic interest [20]. A lot of research has been made to isolate and characterize isolated single constituents of traditional herbal medicine to find their rationale for therapeutic uses. However, our data together with those of others [21] provide legitimation to introduce a new generation of phytopharmaceuticals to treat diseases that have hitherto been treated using synthetic drugs alone. The therapeutic synergy observed with plant extracts results in the requirement for a lower amount of active components, with consequent reduced adverse effects.

\section{Conclusion}

In conclusion, we recommend standardized plant extract of the Cannabis clone 202 for treatment of various inflammatory conditions.

\section{Acknowledgements}

The authors would like to thank Dr. Ronit Sionov for her valuable editorial assistance.

\section{Conflict of Interest}

Prof. Ruth Gallily has been a consultant for Tikun Olam since 2013, and has received a research grant during the years 2012-2014 from Tikun Olam, Israel. There is no conflict of interest.

\section{References}

[1] Hazekamp, A., Ware, M.A., Muller-Vahl, K.R., Abrams, D. and Grotenhermen, F. (2013) The Medicinal Use of Cannabis and Cannabinoids-An International Cross-Sectional Survey on Administration Forms. Journal of Psychoactive Drugs, 45, 199-210. http://dx.doi.org/10.1080/02791072.2013.805976

[2] Mechoulam, R. (2012) Cannabis-A Valuable Drug That Deserves Better Treatment. Mayo Clinic Proceedings, 87, 107-109. http://dx.doi.org/10.1016/j.mayocp.2011.12.002

[3] Greydanus, D.E., Hawver, E.K., Greydanus, M.M. and Merrick, J. (2013) Marijuana: Current Concepts. Frontiers in Public Health, 1, 42. http://dx.doi.org/10.3389/fpubh.2013.00042

[4] Syed, Y.Y., McKeage, K. and Scott, L.J. (2014) Delta-9-Tetrahydrocannabinol/Cannabidiol (Sativex ${ }^{\mathbb{R}}$ ): A Review of Its Use in Patients with Moderate to Severe Spasticity Due to Multiple Sclerosis. Drugs, 74, 563-578. http://dx.doi.org/10.1007/s40265-014-0197-5

[5] Brenneisen, R. (2007) Chemistry and Analysis of Phytocannabinoids and Other Cannabis Constituents. Marijuana and the Cannabinoids, Chapter 2, 17-49. http://dx.doi.org/10.1007/978-1-59259-947-9 2

[6] Pertwee, R.G. (2008) The Diverse CB1 and CB2 Receptor Pharmacology of Three Plant Cannabinoids: Delta9-Tetrahydrocannabinol, Cannabidiol and Delta9-Tetrahydrocannabivarin. British Journal of Pharmacology, 153, 199-215. http://dx.doi.org/10.1038/sj.bjp.0707442

[7] Pacher, P. and Mechoulam, R. (2011) Is Lipid Signaling through Cannabinoid 2 Receptors Part of a Protective System? Progress in Lipid Research, 50, 193-211. http://dx.doi.org/10.1016/j.plipres.2011.01.001

[8] Malfait, A.M., Gallily, R., Sumariwalla, P.F., Malik, A.S., Andreakos, E., Mechoulam, R. and Feldmann, M. (2000) The Nonpsychoactive Cannabis Constituent Cannabidiol Is an Oral Anti-Arthritic Therapeutic in Murine Collagen-Induced Arthritis. Proceedings of the National Academy of Sciences USA, 97, 9561-9566. 
http://dx.doi.org/10.1073/pnas.160105897

[9] Mechoulam, R., Peters, M., Murillo-Rodriguez, E. and Hanus, L.O. (2007) Cannabidiol—Recent Advances. Chemistry \& Biodiversity, 4, 1678-1692. http://dx.doi.org/10.1002/cbdv.200790147

[10] Weiss, L., Zeira, M., Reich, S., Slavin, S., Raz, I., Mechoulam, R. and Gallily, R. (2008) Cannabidiol Arrests Onset of Autoimmune Diabetes in NOD Mice. Neuropharmacology, 54, 244-249. http://dx.doi.org/10.1016/j.neuropharm.2007.06.029

[11] Kozela, E., Lev, N., Kaushansky, N., Eilam, R., Rimmerman, N., Levy, R., Ben-Nun, A., Juknat, A. and Vogel, Z. (2011) Cannabidiol Inhibits Pathogenic T Cells, Decreases Spinal Microglial Activation and Ameliorates Multiple Sclerosis-Like Disease in C57BL/6 Mice. British Journal of Pharmacology, 163, 1507-1519. http://dx.doi.org/10.1111/j.1476-5381.2011.01379.x

[12] Esposito, G., Filippis, D.D., Cirillo, C., Iuvone, T., Capoccia, E., Scuderi, C., Steardo, A., Cuomo, R. and Steardo, L. (2013) Cannabidiol in Inflammatory Bowel Diseases: A Brief Overview. Phytotherapy Research, 27, 633-636. http://dx.doi.org/10.1002/ptr.4781

[13] Jamontt, J.M., Molleman, A., Pertwee, R.G. and Parsons, M.E. (2010) The Effects of Delta-Tetrahydrocannabinol and Cannabidiol Alone and in Combination on Damage, Inflammation and in Vitro Motility Disturbances in Rat Colitis. British Journal of Pharmacology, 160, 712-723. http://dx.doi.org/10.1111/j.1476-5381.2010.00791.x

[14] Gadó, K. and Gigler, G. (1991) Zymosan Inflammation: A New Method Suitable for Evaluating New Anti-Inflammatory Drugs. Agents and Actions, 32, 119-121. http://dx.doi.org/10.1007/BF01983335

[15] Grotenhermen, F. (2003) Pharmacokinetics and Pharmacodynamics of Cannabinoids. Clinical Pharmacokinetics, 42, 327-360. http://dx.doi.org/10.2165/00003088-200342040-00003

[16] Rocha, A.C., Fernandes, E.S., Quintao, N.L., Campos, M.M. and Calixto, J.B. (2006) Relevance of Tumour Necrosis Factor-Alpha for the Inflammatory and Nociceptive Responses Evoked by Carrageenan in the Mouse Paw. British Journal of Pharmacology, 148, 688-695. http://dx.doi.org/10.1038/sj.bjp.0706775

[17] Romano, B., Borrelli, F., Pagano, E., Cascio, M.G., Pertwee, R.G. and Izzo, A.A. (2014) Inhibition of Colon Carcinogenesis by a Standardized Cannabis Sativa Extract with High Content of Cannabidiol. Phytomedicine, 21, 631-639. http://dx.doi.org/10.1016/j.phymed.2013.11.006

[18] Capasso, R., Aviello, G., Borrelli, F., Romano, B., Ferro, M., Castaldo, L., Montanaro, V., Altieri, V. and Izzo, A.A. (2011) Inhibitory Effect of Standardized Cannabis Sativa Extract and Its Ingredient Cannabidiol on Rat and Human Bladder Contractility. Urology, 77, 1006.e9-1006e15. http://dx.doi.org/10.1016/j.urology.2010.12.006

[19] De Petrocellis, L., Ligresti, A., Schiano Moriello, A., Iappelli, M., Verde, R., Stott, C.G., Cristino, L., Orlando, P. and Di Marzo, V. (2013) Non-THC Cannabinoids Inhibit Prostate Carcinoma Growth in Vitro and in Vivo: Pro-Apoptotic Effects and Underlying Mechanisms. British Journal of Pharmacology, 168, 79-102. http://dx.doi.org/10.1111/j.1476-5381.2012.02027.x

[20] Russo, E.B. (2011) Taming THC: Potential Cannabis Synergy and Phytocannabinoid-Terpenoid Entourage Effects. British Journal of Pharmacology, 163, 1344-1364. http://dx.doi.org/10.1111/j.1476-5381.2011.01238.x

[21] Wagner, H. and Ulrich-Merzenich, G. (2009) Synergy Research: Approaching a New Generation of Phytopharmaceuticals. Phytomedicine, 16, 97-110. http://dx.doi.org/10.1016/j.phymed.2008.12.018 
Scientific Research Publishing (SCIRP) is one of the largest Open Access journal publishers. It is currently publishing more than 200 open access, online, peer-reviewed journals covering a wide range of academic disciplines. SCIRP serves the worldwide academic communities and contributes to the progress and application of science with its publication.

Other selected journals from SCIRP are listed as below. Submit your manuscript to us via either submit@scirp.org or Online Submission Portal.
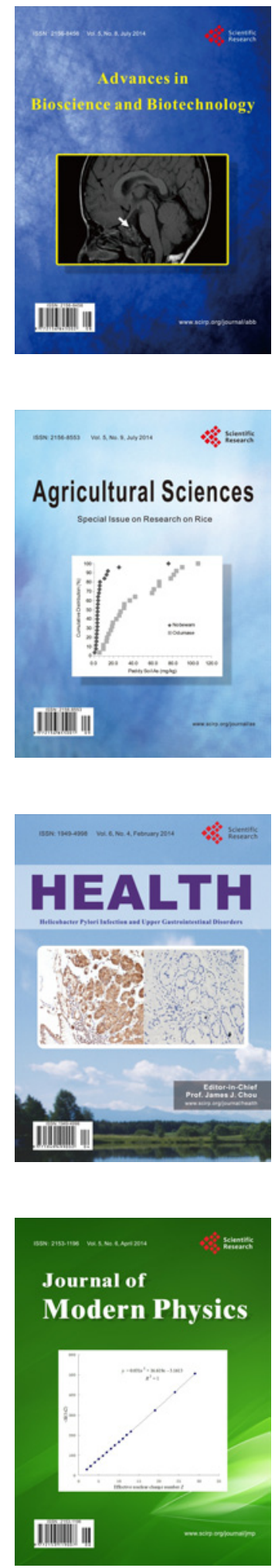
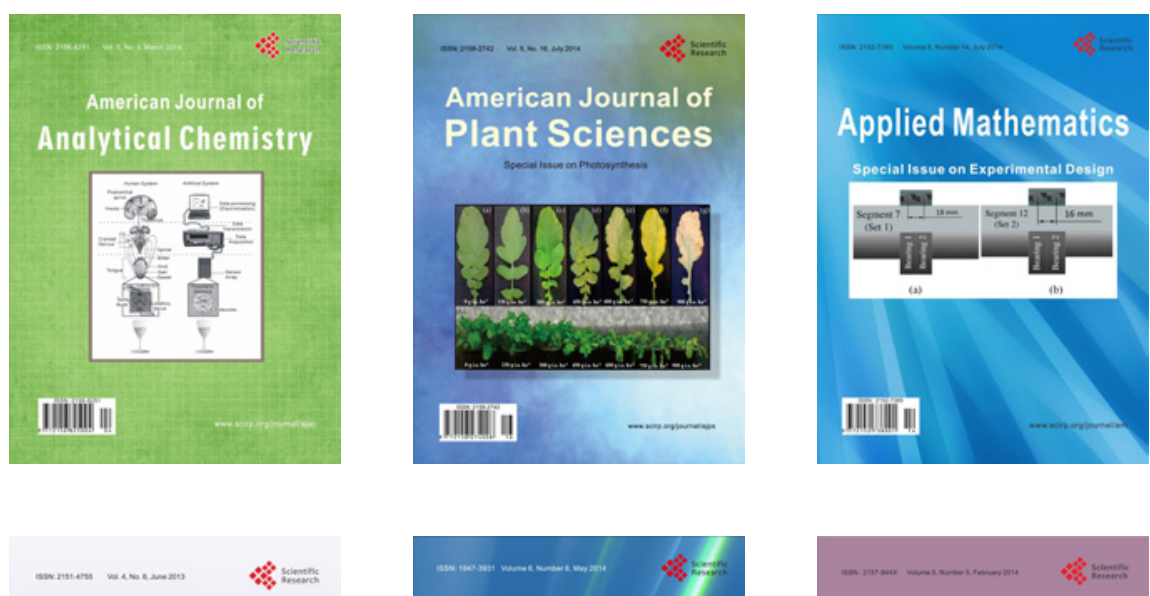

Creative Education
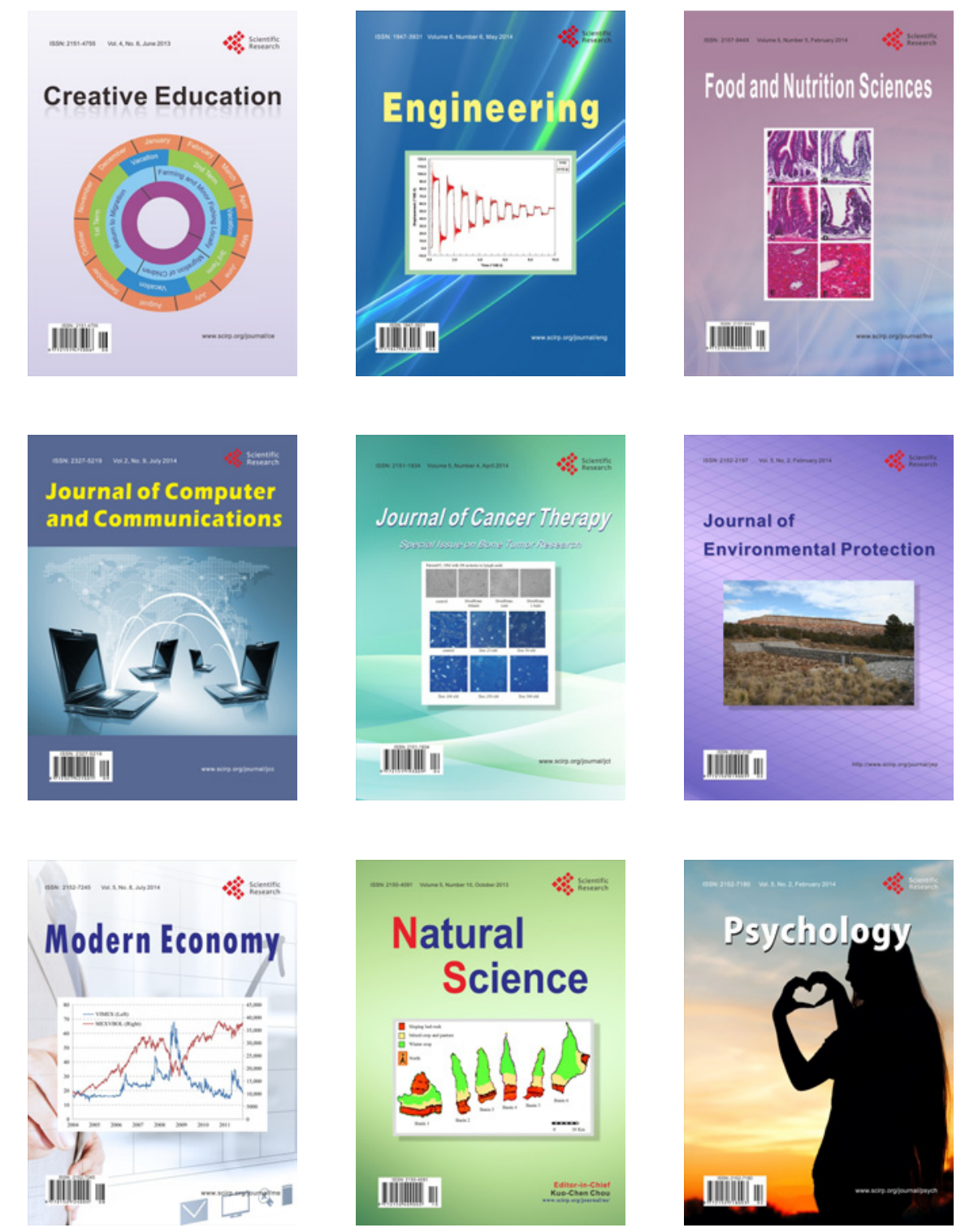